\title{
A Holistic Student-Centered Approach to Retaining and Graduating Engi- neers at a Midwest University
}

\section{Dr. Ma Zenia N. Agustin, Southern Illinois University - Edwardsville}

Dr. Zenia Agustin is a Professor in the Department of Mathematics and Statistics at Southern Illinois University Edwardsville. Currently, she is the Director of General Education and Integrative Studies for the university and Director of the Actuarial Science program for the department. Her research interests include reliability and survival analysis and in particular, goodness-of-fit testing for recurrent events.

\section{Dr. Marcus Agustin, Southern Illinois University - Edwardsville}

Dr. Marcus Agustin is a Professor of Mathematics and Statistics at Southern Illinois University Edwardsville. His research interests include Statistics, Reliability, and Survival Analysis. Courses he has taught at SIUE include Calculus I-III, Linear Algebra, Operations Research: Stochastic Models, Introduction to Mathematical Statistics I\&II, Reliability Engineering, and Reliability Theory.

\section{Dr. George Pelekanos, Southern Illinois University}

Dr. George Pelekanos is a Professor in the Department of Mathematics and Statistics at Southern Illinois University Edwardsville. He obtained his Ph. D degree in Applied Mathematics from the University of Delaware in 1997. His research interests include inverse scattering and mathematics education.

\section{Dr. Cem Karacal, Southern Illinois University - Edwardsville}

Dr. Cem Karacal is a Professor of Industrial Engineering and Dean of the School of Engineering at Southern Illinois University Edwardsville. He obtained his Ph.D. and M.S. degrees from Oklahoma State University in 1991 and 1986, respectively. His received his B.Sc. degree from Middle East Technical University, Ankara, Turkey in 1982. He has experience in industry and academia. His main research and teaching interest areas are simulation modeling, quality control, operations research, and facilities layout. Before joining to SIUE he worked at Rochester Institute of Technology as a faculty member and Computer Integrated Manufacturing System project coordinator for RIT's integrated circuit factory. He is a senior member of IIE and SME, and a member of ASEE, Alpha Pi Mu and Tau Beta Pi. 


\title{
A holistic student-centered approach to retaining and graduating engineers at Southern Illinois University Edwardsville
}

\author{
Ma Zenia Agustin ${ }^{1}$, Marcus Agustin ${ }^{1}$, George Pelekanos ${ }^{1}$, Cem Karacal $^{2}$ \\ Southern Illinois University Edwardsville, Edwardsville, IL \\ ${ }^{1}$ Department of Mathematics and Statistics \\ ${ }^{2}$ School of Engineering
}

\begin{abstract}
This work in progress describes a comprehensive set of activities geared towards incoming freshman engineering majors to help them transition to the university setting and set a good foundation for their early mathematics courses. The activities undertaken in this NSF-supported STEP grant can be classified in the following major areas: (i) enhancements in the delivery of mathematics courses to improve the rate of success, (ii) engaging students to the engineering community as early as possible through mentoring and other activities, and (iii) improving the freshman engineering course to invoke lasting interest in engineering.
\end{abstract}

The project is now in its third year. The passing rates in the Calculus courses showed noteworthy improvements and more so, the percentage of students earning grades of A or B increased significantly. In particular, the passing rates in Calculus I for students involved in the project compared to those who are not are $69.7 \%$ and $56.7 \%$, respectively. The corresponding passing rates for Calculus II are $84.2 \%$ and $66.7 \%$, respectively. In addition, the percentage of students who earned grades of $\mathrm{A}$ or $\mathrm{B}$ for those involved in the project compared to those who are not are $46.4 \%$ and $35.0 \%$, respectively in Calculus I and $57.3 \%$ and $38.7 \%$, respectively in Calculus II.

Adjustments continue to be made to achieve the project goals. Furthermore, as the project activities required significant coordination among different campus offices and academic departments, changes are made in processes to facilitate collaboration. The project activities have contributed to our improved retention rates and even helped us recruit more and better prepared students.

\section{Introduction}

According to the U.S. Bureau of Labor Statistics projections, almost all engineering disciplines will experience significant growth in the coming years. In Civil and Industrial engineering, the expected rates of employment growth are as high as $24 \%$ and $14 \%$, respectively. As the interest in engineering education in the U.S. remains steady at best over the last few decades, the implications of projected growth can have serious undesired consequences for the U.S. economy and the society. Furthermore, the number of engineering degrees awarded to underrepresented groups is far below the desired levels. The recruitment and retention of engineering students, 
especially those from underrepresented groups, play a strategically important role for the future well-being of the nation. ${ }^{1-2}$ Universities have to take necessary steps to create a nurturing learning environment where students of various backgrounds and skill levels are provided support systems that give them opportunities for success in a rigorous engineering curriculum.

The center piece of this project is the enhancement to the delivery of Calculus I and Calculus II courses. Research has shown that one of the major barriers to retention for students interested in STEM majors is their performance in their early mathematics courses such as Calculus I. ${ }^{3}$. Failure to complete Calculus I successfully is a strong determinant in a student's decision to remain an engineering major or even to stay at a university. It is therefore imperative to provide students with a strong foundation in the first semester Calculus I and to provide the necessary support in order for them to be successful.

Active learning, engagement in the classroom, and peer-to-peer collaboration have delivered promising results in freshman level STEM courses. ${ }^{4-7}$ For math courses, two of the most commonly used approaches are supplemental instruction (SI) and peer-led team learning (PLTL). The SI approach, developed at University of Missouri-Kansas City, focuses on at-risk courses and consists of voluntary sessions led by undergraduate students. At-risk courses are gateway courses which historically have failure or withdrawal rates of at least $30 \%$. Undergraduate students who have taken the course and earned grades of A or B are recruited and trained to be SI Leaders who function as undergraduate teaching assistants during the SI sessions, The SI Leaders are responsible for the activities during the SI sessions, including the problems that are given to students. ${ }^{8}$

On the other hand, the PLTL approach, developed at the City College of New York, employs a small-group collaborative learning model facilitated by a trained undergraduate peer leader. Small groups of students are provided materials that encourage critical thinking, deeper analysis and thoughtful deliberation among members so they can, as a group, develop mastery of concepts and skills. While the SI sessions are voluntary for students, there is variability in the PLTL set-up in terms of student attendance. ${ }^{9}$

The current project implemented a learning model that blends the best features of the SI and PLTL frameworks. In this paper, this new learning approach is described, adjustments made to accommodate coordination and logistic issues are explained, and the impact on student performance is presented.

\section{Description of Enrichment Sessions}

Enrichment sessions (ES) are required 75-minute small group sessions facilitated by undergraduate ES Leaders. These sessions are not optional and appear on the student's schedule when they register for engineering sections of the course. These sessions are intended to develop collaborative problem solving skills and to provide students with opportunities to practice independent thinking and clear articulation of ideas. This is the time when students are 
encouraged to think through problems deeply, discuss possible approaches with their group, and take risks with various problem-solving strategies.

Calculus I and II courses meet for 80-minute lectures with the instructor on Mondays, Wednesdays, and Fridays. During the Fall 2013 Calculus I and Spring 2014 Calculus II courses, the sessions were held right after the lectures on Mondays and Wednesdays. However, construction on several campus buildings planned for the academic year 2014-2015 made the availability of classrooms for long periods of time and outside of the normal schedule grid difficult. Thus, the ES were moved to Tuesdays and Thursdays for the Fall 2014 Calculus I courses and the Spring 2015 Calculus II courses. The switch in days produced no significant differences in student attendance patterns as well as course performance results.

The ES Leaders are recruited from engineering majors who have previously taken the course, performed well, and demonstrated effective communication skills. Potential ES Leaders go through an intensive interview process where they are asked to prepare a brief blackboard presentation of a mathematical concept such as the concept of a derivative where the intended audience consists of freshman Calculus I students meeting the concept for the first time, and are given scenarios to evaluate their small group communication skills. The successful ES Leader applicants are then given training on professionalism, dealing with various student personalities, and strategies for facilitating effective small group discussions before the start of each semester. During the semester, weekly meetings are held between the ES Leaders and the project team to discuss what went well during the past week, what can be improved, issues that they faced and how they resolved them, and feedback regarding mistakes that students commonly made as well as concepts that the students struggled with. The ES Leaders are required to attend at least one lecture per week so they are attuned to the instructor's approach to course material. Materials for the ES are prepared by a math professor in the project team who collaborates with the course instructors to make sure that the ES and lecture materials coincide. The ES Leaders receive a copy of the problems that will be given to students ahead of time and they submit their solutions to the project team at least two days prior to the ES. This practice ensures that the ES Leaders themselves know how to solve the problems and more importantly, can think of ways to guide the students to recognize nuances in problem solving approaches, if any.

The main role of the ES Leaders is to promote discussion among group members and serve as positive role models. They are expected to (1) encourage students to utilize a variety of strategies to solve problems, (2) provide suggestions and feedback to students as they collaboratively try to derive solutions, (3) offer timely assistance, without providing the answer, (4) set an atmosphere that fosters respect for all points of view, and (5) ensure that all students are actively participating.

A typical Calculus I or Calculus II course consists of roughly 60 students. Four ES Leaders are assigned to each class. For each session, students are divided into groups of 4 or 5 and are instructed to proceed to various parts of the large classroom. Group members turn their desks 
around so they are all facing each other. Each student is provided a worksheet with a mix of conceptual and computational problems which are carefully drafted to reinforce skills and to deepen and expand conceptual understanding of lecture materials. Problems for each session reinforce course material covered in the most recent lecture as well as previous material that students had some difficulty grasping. Group members work collaboratively with each other, while ES Leaders move around the room to make sure everyone in a group is contributing to the discussion, to encourage the use of various problem-solving strategies, and to provide some direction, if needed. It should be noted that while group members help each other think through problems and arrive at sound solutions, each student is responsible for writing up his/her worksheet solution that is submitted and graded. Worksheet scores account for some portion of the course grade ranging from $5 \%$ to $15 \%$, depending on the instructor. The composition of the groups changes every week to facilitate getting to know their classmates and to help establish network connections among engineering majors. The ES framework therefore provides both academic and social support for freshmen. For student retention, it is crucial that freshmen feel connected to their peers, their major field, and the university as a whole. This initial connection will pave the way for them to become engaged in their learning experience.

The ES model provides an environment where students are actively involved in the learning process, encouraged to use various problem-solving strategies, and given opportunities to develop effective ways to communicate scientific ideas and work as a team toward achieving a common objective.

During the fall semesters, two sections of Calculus I with ES are offered to incoming freshman engineering majors. During the following spring semester, two sections of Calculus II with ES are offered to engineering majors. Even though these sections are marked as engineering sections, there were a handful of non-engineering students who managed to get into these sections. For this study, only freshman engineering majors are considered. In this paper, the aggregate results for two freshman engineering cohorts are presented.

\section{Results of ES Study}

The Fall 2013 and Fall 2014 freshman engineering cohorts who registered in Calculus I consisted of 171 and 141 students, respectively. The performance of students who opted to register for the ES sections are compared to those who chose the non-ES sections. Non-ES sections have either the traditional recitation sessions or computer laboratories that use the software Mathematica. Both of these options are conducted by graduate teaching assistants.

To gauge the effectiveness of the ES approach, the ES group and the non-ES group were compared relative to two measures: proportion of students who passed Calculus $\mathrm{I}$, that is proportion who earned letter grades of $\mathrm{A}, \mathrm{B}$, or $\mathrm{C}$ and proportion of students who earned grades of A or B. It has been shown in the literature that students who earn grades of at least B in Calculus I tend to perform better in subsequent mathematics and physics courses ${ }^{3}$. The results of 
the statistical analysis are presented in Table 1, where the $p$-value corresponds to a one-sided test for two proportions. The proportion of freshman engineering majors who completed Calculus I with a grade of at least $\mathrm{C}$ is significantly higher for the ES group compared to the non-ES group. In addition, the proportion of engineering majors who earn grades of at least $\mathrm{B}$ is also significantly higher for the ES group compared to the non-ES group. The grade distribution for Calculus I is presented in Figure 1, where W, WP, WF, UW denote withdrew, withdrew passing, withdrew failing, and unauthorized withdrawal, respectively. Withdrew means that the student officially dropped the class by the end of the $10^{\text {th }}$ week of the semester; withdrew passing means that the student officially dropped the course after the $10^{\text {th }}$ week and had a passing grade at the time of withdrawal; withdrew failing means that the student officially dropped the course after the $10^{\text {th }}$ week and had a failing grade at the time of withdrawal; and unauthorized withdrawal means that the student abandoned the class without officially dropping. Note that the non-ES group has a higher withdrawal percentage than the ES group.

Table 1: Calculus I - Comparison between ES and non-ES groups

\begin{tabular}{|l|c|c|c|c|}
\hline & ES & Non-ES & Test Statistic & $p$-value \\
\hline $\begin{array}{l}\text { Proportion of } \\
\text { students who } \\
\text { earned grades of }\end{array}$ & 0.6968 & 0.5669 & 2.40 & $0.008^{*}$ \\
A, B, or C & & & & \\
\hline $\begin{array}{l}\text { Proportion of } \\
\text { students who } \\
\text { earned grades of } \\
\text { A or B }\end{array}$ & 0.4645 & 0.3503 & 2.07 & $0.019^{*}$ \\
\hline
\end{tabular}

Figure 1: Calculus I grade distribution - Comparison between ES and non-ES groups 


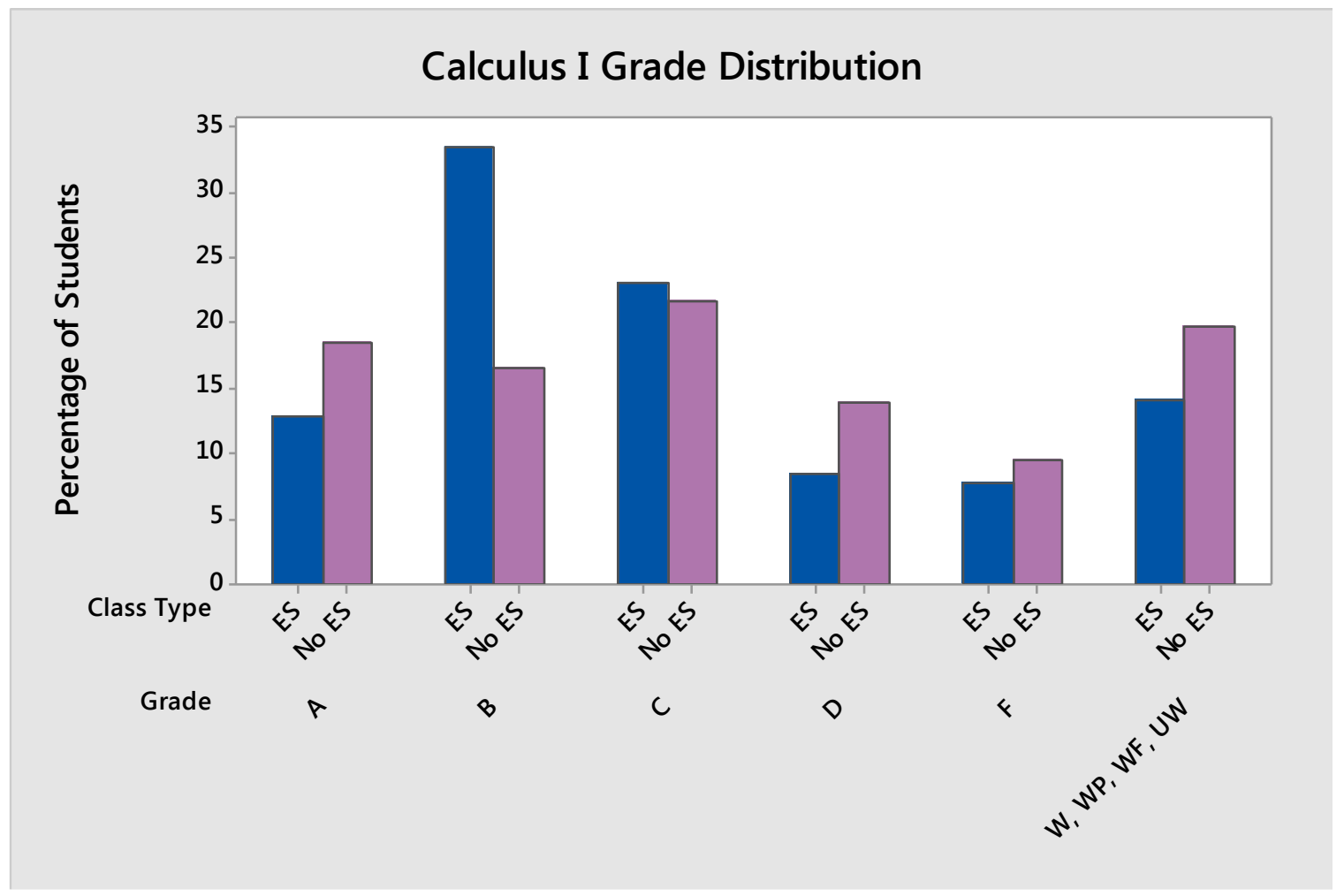

For engineering majors, the second math course during their freshman year is Calculus II. Out of the Fall 2013 freshman cohort, 98 passed Calculus I but only 90 went on to register for Calculus II in the Spring 2014 semester. For the Fall 2014 freshman cohort, 99 passed Calculus I, 92 of whom continued on to Calculus II in the next semester. The students who went on to Calculus II had a choice between the ES and non-ES sections. There does not appear to be a difference in the student characteristics between the two groups as students typically choose the section that best fits their schedule. The aggregate results for Calculus II are summarized in Table 2. Note that for both measures, the proportion corresponding to the ES group is significantly higher than that for the non-ES group. The grade distribution for Calculus II corresponding to the ES and non-ES groups is given in Figure 2.

Table 2: Calculus II - Comparison between ES and non-ES groups

\begin{tabular}{|l|c|c|c|c|}
\hline & ES & Non-ES & Test Statistic & $p$-value \\
\hline $\begin{array}{l}\text { Proportion of } \\
\text { students who } \\
\text { earned grades of } \\
\text { A, B, or C }\end{array}$ & 0.8423 & 0.6667 & 2.83 & $0.002 *$ \\
\hline $\begin{array}{l}\text { Proportion of } \\
\text { students who } \\
\text { earned grades of } \\
\text { A or B }\end{array}$ & 0.5730 & 0.3871 & 2.55 & $0.005^{*}$ \\
\hline
\end{tabular}




\section{Figure 2: Calculus II grade distribution - Comparison between ES and non-ES groups}

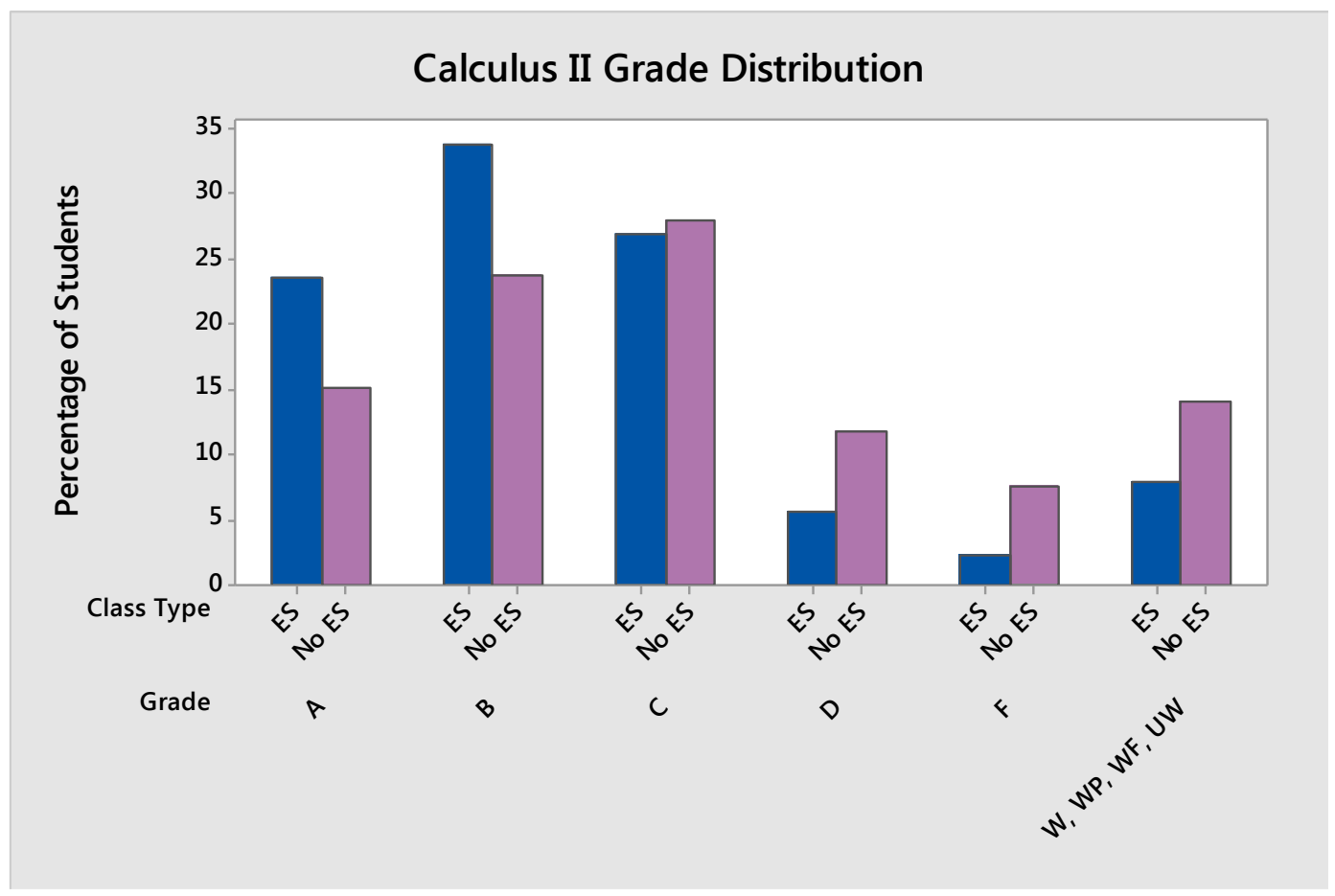

For engineering majors, their academic performance during the first year sets the tone for future success. It is therefore important to measure the effect of the ES approach on the probability of successfully completing Calculus II. In order to understand the effect of the ES approach on the probability of passing Calculus II, a logistic regression was performed. The response variable corresponds to whether a student passed Calculus II or not, where passing is defined to be a grade of $\mathrm{C}$ or better. Thus the response variable is binary with a value of 1 if the student passed Calculus II and 0 otherwise. Two binary predictor variables were used and are defined as follows: $X_{1}$ is 1 if the student had ES in Calculus I and 0 otherwise, and $X_{2}$ is 1 if the student had ES in Calculus II and 0 otherwise. The resulting fitted regression equation is

$$
P(Y=1)=\frac{\exp (0.399+0.607 X 1+0.961 X 2)}{1+\exp (0.399+0.607 X 1+0.961 X 2)} .
$$

Thus the estimated probability of passing Calculus II as a function of having availed of ES is summarized in Table 3. Note that having ES in just one course significantly increases the probability of passing Calculus II.

Table 3: Probability of passing Calculus II as a function of taking ES

\begin{tabular}{|c|c|c|}
\hline ES in Calculus I & ES in Calculus II & $\begin{array}{c}\text { Estimated probability of } \\
\text { passing Calculus II }\end{array}$ \\
\hline No & No & 0.5984 \\
\hline Yes & No & 0.7322 \\
\hline
\end{tabular}




\begin{tabular}{|c|c|c|}
\hline No & Yes & 0.7958 \\
\hline Yes & Yes & 0.8773 \\
\hline
\end{tabular}

These results show the potential of peer-led interactive problem-solving in improving student understanding of important concepts and skills which in turn lead to better performance and retention.

\section{Tutoring Services}

In addition to the ES, engineering majors in these two cohorts had access to both face-to-face and online tutoring services provided by undergraduate engineering peers. These tutoring services which are free of charge are available during daytime as well as evening hours. While the university's math resources center provides tutoring services to all students during daytime in the Student Success Center, engineering tutors supported via STEP funds are stationed in the freshman residence hall Sunday through Thursday evenings from 6-9 pm. The tutors are recruited using a process very similar to ES leaders. The logbook records indicate that the utilization rate of face-to-face tutors are higher in the fall semesters with the same set of students persistently taking advantage of the services. However, contrary to the project team's intuition, the online tutoring services provided between 9-11 pm did not gain much traction. In 2013, Skype was used as the platform for online connection with the tutor. The feedback received from the students indicated that some were conscious about their appearances and did not want to take advantage of the services. As a result, in 2014, we subscribed to an online software called Tutorbox where video connection was an option. However, the utilization rate for the service did not improve and we decided to cancel the online tutoring services in 2015.

\section{Engagement to the engineering community}

A Focus Interest Community (FIC) is a dedicated wing of a residence hall where freshman residents who share common interests form a support network. Upper class engineering majors serve as mentors to all engineering freshmen via their designated group of mentees and use the engineering FIC as their home base for various activities. Mentors provide academic support as well as plan social activities to help freshmen become engaged and connected with the university in general and with the engineering community in particular. Approximately 120-150 students live in an engineering FIC in each academic year. The original mentoring program required 7 mentors live in the FIC with their mentees and connect more personally. The difficulty of recruiting qualified juniors and seniors who are willing to live in the freshman residence hall made the idea infeasible. We now require mentors to have experience with university housing, but not necessarily live in the residence halls.

As early as their freshman year, students are encouraged to participate in student design teams and professional organizations based on their area of interest. The School of Engineering currently has 27 professional organizations and student design teams. These teams and organizations participate in regional, national, and international competitions and meetings. Participation in professional organizations give students an excellent opportunity for hands-on 
experience in "doing" engineering as well as for connecting with the engineering community. Each design team usually has around 15 participants who actively recruit freshmen to their teams. The participation rate in professional organizations is even higher. These organizations encourage freshmen to get involved in various professional and community projects they conduct. The mentors, many of whom are members of professional societies and design teams, helped us increase the rate at which the freshmen participate in student organizations.

Freshmen also have the chance to request an engineering faculty mentor as well as interact with engineers from local companies on a regular basis. These interactions definitely help students build their professional network early in their studies and provide them role models. . The initial connections with the engineering profession serve as an effective support tool to engage freshmen. In 2013, several engineers, some of whom are our own alumni, from local companies met with the freshman cohort throughout the academic year in casual settings to share their professional experiences and interact with the students. In 2014, two of the largest technology companies in the region with international name recognition sent several of their engineers to visit with our freshman class. All of these events were very well attended and made an impact on student's understanding of the profession and persistence in engineering.

\section{Freshmen Engineering Course}

The impact of redesigning the freshmen engineering course also facilitated the engagement of freshmen. The course that was originally taught by an adjunct faculty who had significant industrial experience as a motivational course and lacked focus is converted to a team taught course. A team of faculty members with proven teaching skills from four engineering majors offered in the school claimed ownership of the course and developed four project-based modules. The course is offered in four sections with 30 students each during fall and spring semesters as a freshman seminar course that also helps with student's acclimation to college life and institutional culture. The instructors rotate between sections and teach technical background material directly relevant to their hands-on projects thereby not only giving students a chance to meet a faculty member from each department, but also learn from an expert in the field. The detailed impact of the new freshman engineering course is discussed in a separate paper submitted to the ASEE 2016 Annual Conference.

\section{Conclusions and Future Directions}

After two full years of implementation, the holistic approach shows promising results for improving student performance in Calculus I and II and engaging freshmen to the engineering community and profession. The improved performance and engagement in the freshman year definitely contribute to a higher retention and hopefully graduation rates. A positive freshman year experience particularly in early mathematics courses sets a solid foundation for and instills confidence in tackling future course work. The project is still in its early stages that no conclusions can be made regarding graduation rates. For each freshman cohort, the progress of each student will continue to be tracked. 
In the fall 2014 semester, 197 incoming engineering freshmen who attended the university's springboard to success program declared one of the disciplines in engineering as their majors. The mathematics grades and academic performance of the fall 2014 Springboard freshmen are tracked by the Engineering Student Services office. Of the 197 students, 178 (90\% retention rate) completed the spring 2015 semester in the School of Engineering according to the registrar reports for spring 2015. This is an improvement over the first year of the project in which the retention rate was $87 \%$. Both of these numbers show the impact of the STEP project that resulted in noteworthy improvements over the university's historical engineering retention rate of $76 \%$. The results from the ES approach is consistent with what has been reported in the literature concerning the use of small group interactive learning models facilitated by undergraduate peers. ${ }^{4-7}$ Exposing freshmen to collaborative problem solving in small groups allows them to develop skills in independent thinking, communicating their ideas, navigating differences in approaches, and working with different personalities. These are skills that are crucial to being successful in the engineering profession where one typically works as part of a project team.

Students who availed of the courses with ES realized the benefit of the experience and are eager to give back to the program. Majority of our current ES Leaders are products of these first two years of the ES model and they serve as effective ambassadors of the approach. These ES Leaders are positive role models for the freshmen.

The Department of Mathematics and Statistics recently instituted common final exams for all Calculus I classes. It will be interesting to compare the final exam scores of the students who availed of classes with ES and those who did not. Preliminary results from Fall 2015 are encouraging.

Since initial results have shown the significant positive impact of ES in Calculus I and II for incoming freshmen, the goal is to eventually have all incoming freshman engineering majors eligible to take Calculus I be placed in a class with ES. Thus, in Fall 2016, block scheduling will be implemented for the freshman cohort. Every incoming freshman eligible to take Calculus I will be handed a set schedule for required courses, one of which is Calculus I with ES.

\section{Acknowledgements}

The project is supported by National Science Foundation Grant Number 1317651.

\section{Bibliography}

1. National Science Board. The Science and Engineering Workforce: Realizing America's Potential, Publication NSB 03-69, 2003. 
2. Augustine, N. "Rising Above the Gathering Storm: Energizing and Employing America for a Brighter Economic Future", Committee on Science, Engineering, and Public Policy (COSEPUP), 2007.

3. Herzog, S. "Measuring Determinants of Student Return vs. Dropout/Stopout vs. Transfer: A First-to-Second Year Analysis of New Freshmen", Research in Higher Education, pp. 883-928, December 2005.

4. Cheng, D. and Walters, M. "Peer-assisted learning in mathematics: An observational study of student success", Journal of Peer Learning, pp. 23-39, 2009.

5. Steadman, S., Whitman, D.L., and Dewey, B.R. "Power Groups for Engineering Students: A study of Effectiveness", Proceedings of the 2000 ASEE Annual Conference and Exposition, 2000.

6. Jablonski, M., Reisel, J.R., Hosseini, H., Munson, E., and Rineck, L. "Initial Evaluation of the Impact of Math Study Groups on First-Year Student Course Success", Proceedings of the 2011 ASEE Annual Conference and Exposition, 2011.

7. Reisel, J.R., Jablonski, M., and Munson, E. "A Study of the Impact of Peer-Led Team Learning on the First-Year Math Course Performance of Engineering Students", Proceedings of the 2013 ASEE Annual Conference and Exposition, 2013.

8. Martin, D.C. and Arendale, D., "Foundation and Theoretical Framework for Supplemental Instruction" Supplemental Instruction: Improving First-Year Student Success in High-Risk Courses, National Resource Center for the Freshman Year Experience and Students in Transition, Columbia, pp. 41-50, 1993.

9. Gosser, D., Cracolice, M., Kampmeier, J., Roth, V., Strozak, V. and Varma-Nelson, P. Peer-Led Team Learning: A Guidebook, Prentice Hall, 2000. 